Certain eponymous diseases and syndromes have always had a peculiar fascination for the average medical student, yet the majority are comparatively rare and may never be seen by the practitioner during the whole of his professional life. Such is Fournier's gangrene and, in this particular case, the features were most puzzling until the lesion was well advanced.

\section{Case History}

The patient was a previously healthy married man aged $3 \mathrm{I}$, who complained of a very painful, swollen scrotum. He stated that his present illness had begun quite suddenly four days previously with malaise, pyrexia, dysuria and frequency. Soon after this the scrotum had begun to swell, becoming. hot, red and angry-looking. There was no history of trauma or venereal infection, and no significant past history. On examination he looked ill, his temperature was $104.5^{\circ}$ and his pulse rate 140. Apart from furring of the tongue, general examination revealed nothing significant and no loin tenderness. The scrotum was about the size of a grapefruit; it was red, hot and tense, and though he could hardly bear it to be touched, pitting œdema was elicited. The penis was normal, there were no enlarged inguinal glands of note and no evidence of para-aortic lymphadenopathy. Unfortunately the true nature of the condition was not recognised at the time and no photograph was taken. A provisional diagnosis of urinary infection with superadded epididymoorchitis was made, although the presence of scrotal cdema was an unexplained feature of the case.

Progress. The patient was admitted to hospital and treated by bed rest and elevation of the scrotum on elastoplast across the thighs. A course of sulphonamides was commenced, though subsequent investigation showed the urine to be sterile, and the white blood count to be 8,500 per c.mm. with a normal differential count. The Wasserman reaction was negative. By the next day the right side of the scrotum was blue and moist, discharging a particularly offensive smelling fluid. A swab was taken of this and grew a mixed collection consisting of $B$. proteus, coliforms, staphylococci and Ps. pyocyaneus.

During the next few days the skin on the right side of the scrotum became necrotic (Fig. I), and the process spread until almost the whole of the scrotal tissues had become involved by the gangrenous process. By now a diagnosis of Fournier's gangrene had been made with confidence, and the chemotherapy was changed to a combined course of penicillin and streptomycin. Debridement of the scrotum was carried out five days after admission, under general anæsthesia; this was found to be extremely easy, the sloughs lifting away withoute difficulty, leaving the testicles hanging bare but looking quite healthy (Fig. 2). The wound was dressed with glycerine and eusol dressings and began to granulate early, the new scrotal tissues being formed partly fromit the cuff of scrotal skin left and partly from the testicular coverings themselves. Ten days after admission the्r wound looked very healthy indeed and 18 days after admission progress was so rapid that skin grafting, which had previously been considered, in view of the very large raw area, was no longer thought necessary (Fig. 3). The patient was eventually discharged from in-patient treat $\mathcal{N}$ ment exactly one month after admission with only a smalf

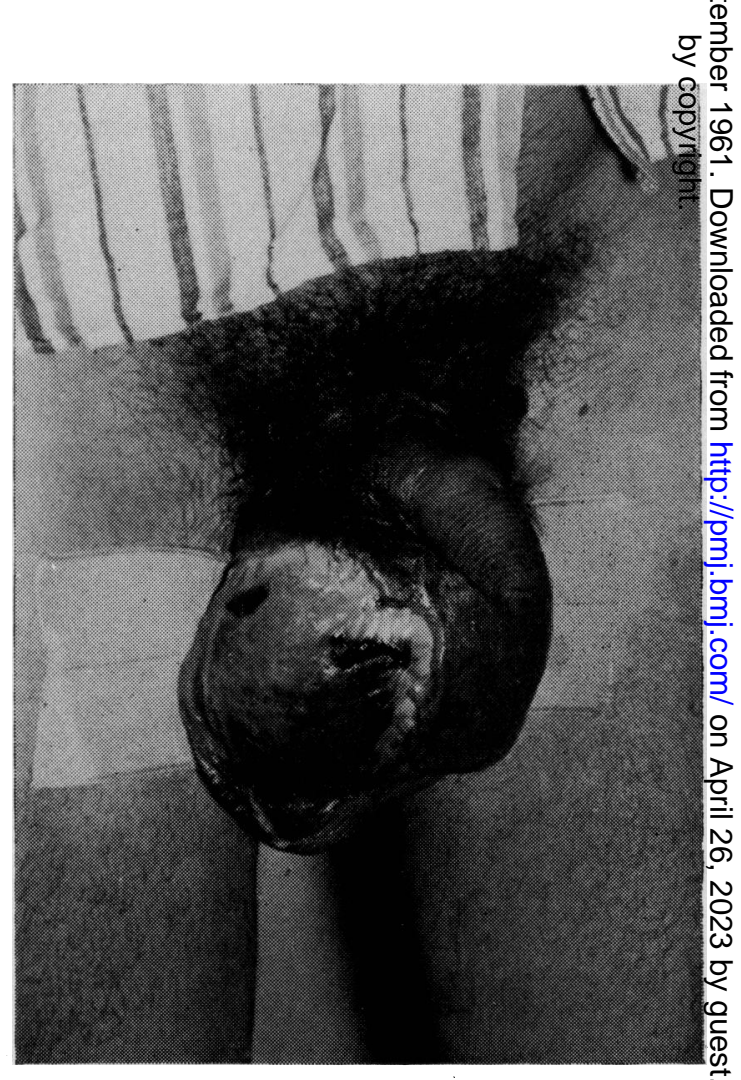

FIG. I.-The gangrenous scrotum a few days after $T$ commencement of the condition. 


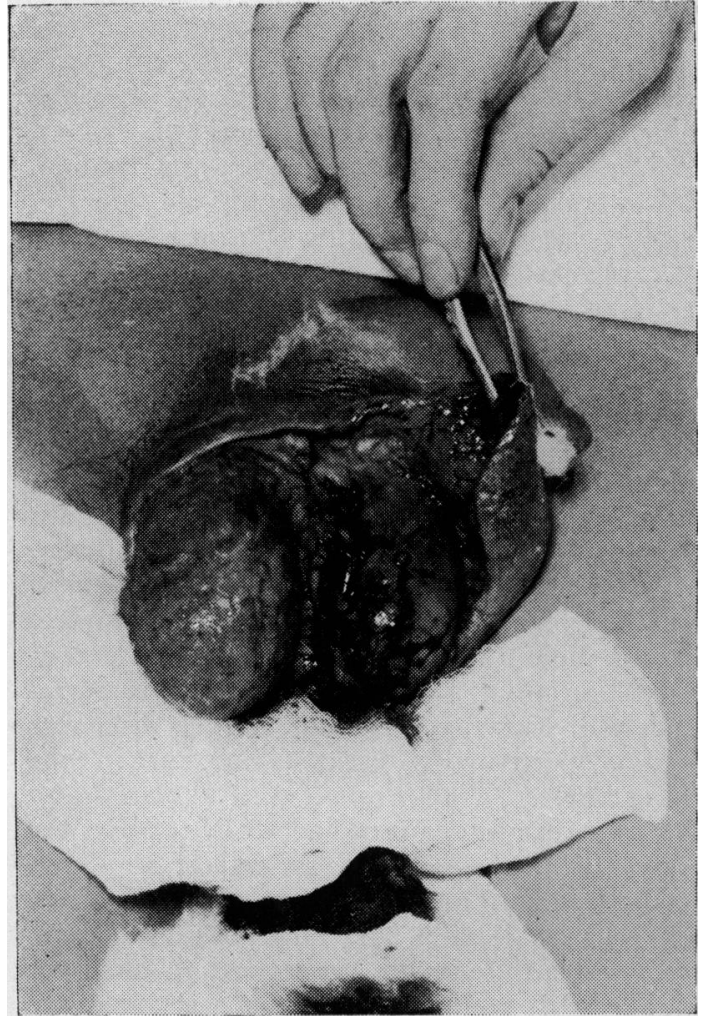

FIG. 2.-Debridement of the scrotum, showing healthy testicles exposed after removal of sloughs.

area of the scrotum unhealed, to continue further dressings at home. Unfortunately nothing further has been heard of this patient as he moved away to another part of the country and our efforts to obtain a final photograph have proved unavailing.

\section{History and Discussion}

The condition was first described by Fournier in 1885 and a translation of his original account is worth reading, the description being couched in phraseology appropriate to the period and making a refreshing change from some present-day medical articles in contemporary journals.

\section{Hospital of St. Louis-Clinic of Professor Fournier. On a Particular Form of Gangrene of the Penis and Scrotum}

Professor Fournier has had under his care a patient with a most peculiar complaint of which examples occur only rarely. This man, previously well, felt at the end of a long journey a slight soreness in the region of the penis, which showed at the same time a little red mark without special characteristics. During the same evening the soreness increased, the penis swelled, and by the following day there were obvious signs of a gangrene, which spread rapidly and in less than three days had attacked the scrotum and the coverings of the penis. It then stopped at this juncture leaving the

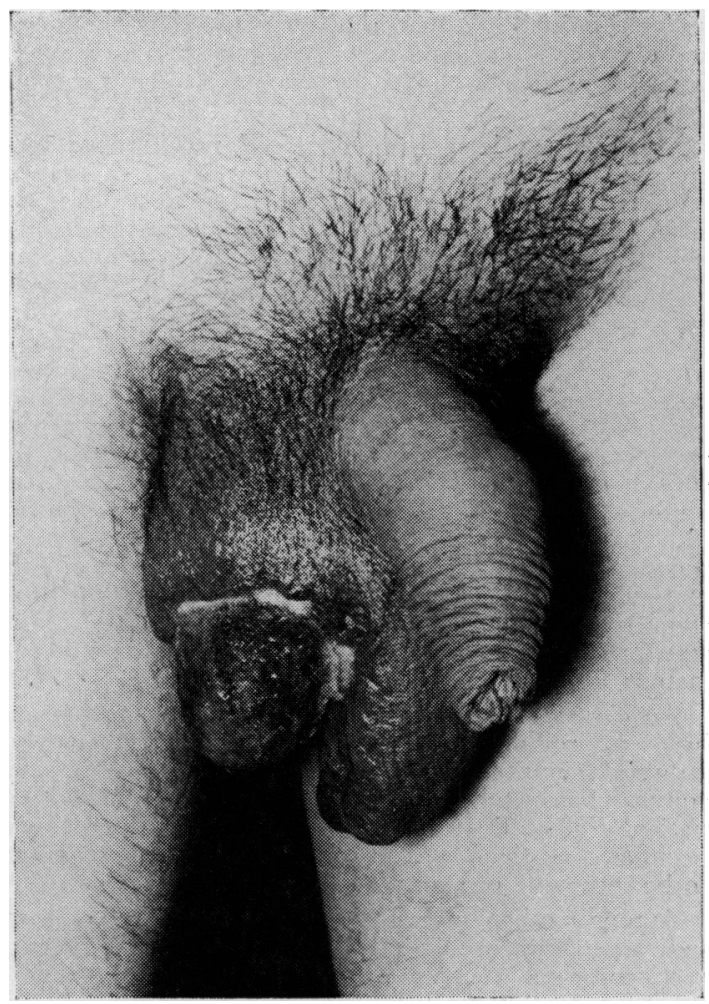

FIG. 3.- The healing scrotum, showing healthy granulations covering the exposed testicle.

testicles bare; a purpuric rash occurred at the same time but the elimination of sloughs soon occurred and the patient was eventually cured.

In the lesson which he devoted to this case $M$. Fournier considered that there was a question here of an entirely new form of gangrene, a type little known, to which could be given the name 'lightning gangrene' or 'acute and serpiginous gangrene' with the negative character of not being explicable by any of the known causes of this affection. This last point can be demonstrated by the examination of divers causes which have been able in certain cases to give rise to gangrene of the penis.

Amongst general causes it is necessary to mention first of all diabetes which predisposes to gangrenes in general, but not more particularly to that of the penis or scrotum. One would expect to note in such cases that there would be an adventitious cause, such as circumcision at the same time, for example. The conclusion from these observations is that it is indispensable to ascertain the sugar content of the urine before carrying out such an operation.

Typhoid or marsh fever (malaria) can be the cause of the same symptoms. There are numbers of cases of it with typhoid fever, and M. Bayer cites in his thesis a case where half the penis was destroyed by the twelfth day of the illness. M. Verneuil has reported the case of a patient attacked by Senegal fever who lost a part of the covering of the penis following a balano-posthitis. The same complication can show itself in other fevers; also cantharides poisoning has caused the same symptom; 
under the double influence of satyriasis thus produced and of repeated coitus, cases of gangrene have resulted, but so exceptionally that there is no need to lay stress on the point.

Local causes have been observed much more frequently than general causes. First of all there are injuries of all kinds, sores, torsions, compressions, all kinds of interruption of the circulation such as paraphimosis, ligatures, rings and all the singular manoeuvres which have been practised on this organ with the most varied intentions. These are the most usual causes, but it has been affirmed on enquiry that gangrene can result from a simple excess of coitus. This scarcely seems possible in ordinary conditions, and to produce such an eventuality a predisposing cause or a really monstrous excess would be necessary. In the first eventuality it could possibly be diabetes, alcoholism, atheroma, or senility which constitutes the predisposing cause. M. Reclus has cited to M. Fournier the case of a man showing a precocious atheroma of all his arteries, and particularly the dorsum of the penis, in which this complication was produced. M. Guyon has observed it equally in the case of an old man of 80 , very atheromatous, after attempts at coitus.

An observation by $M$. Challan shows that gangrene has been produced in an extremely vigorous subject who indulged simultaneously in an excess of alcohol and coitus. By the following day gangrene had set in and the patient died on the ninth day. But apart from such very peculiar conditions acts of venery, by themselves, seem to be incapable of producing gangrene.

Amongst other noteworthy causes it remains only to indicate inflammatory causes, intense and acute inflammations which one sees produced in certain balanoposthites, in urethral lesions, foreign bodies in the urethra, and urinary extravasations. Finally, certain simple chancres are accompanied spontaneously by gangrene, and one also sees this last supervene in glanders and malignant pustule, and it is here that one terminates the enumeration.

But it is easy too to establish that in the patient in question, a vigorous man of 25 , none of these causes existed, and the most detailed enquiries have revealed nothing suspect. This was therefore a case without interpretation had it been absolutely isolated, but $M$. Fournier has already seen four cases of the same type, and $M$. Verneuil has observed a fifth, of such a kind that it is possible to affirm that there exists a peculiar form of gangrene where the prime cause is unknown, but which differs perceptibly from those which have been described hitherto, and which present an evolution and characteristics which should class it entirely separately. There is the probability that it occurs under the influence of a genuine septic inoculation and it is from this point of view comparable to the malignant pustule, even though it has not proved possible so far to verify the manner in which the inoculation occurs.

Be that as it may, the patients observed up to the present were all young, vigorous and healthy, and it was without apparent reason (one of them had not had coitus for many months before) that the symptoms burst out suddenly, accompanied by phenomena generally grave and bringing mortification to the afflicted parts with a lightning rapidity. Limitation takes place equally quickly at the same time as the general state improves. In three cases, however, there was produced soon after the first appearance, a purpura comparable to the purpuras accompanying infections. In spite of the gravity of this condition none of the patients under the care of M. Fournier has died, but a fatal termination has been observed in other cases.
About 300 cases have been reported in the $\frac{2}{3}$ literature, the condition being not uncommon in Nigeria, though rare in the Western world. The age-incidence varies, occurring anywhere from four days to 80 years. It also occurs in women, affecting the vulva. It is a rapidly progressive gangrenous cellulitis affecting the scrotum and $\frac{\bar{\sigma}}{\bar{\sigma}}$ only rarely is the penis or abdominal wall in- $\frac{\bar{\sigma}}{\partial}$ volved, although Fournier's original description $\stackrel{\overparen{Q}}{\Phi}$ does not agree with this observation. The skin and subcutaneous tissues down to Colles's fascia are involved and the condition is apparently self- $\stackrel{\circ}{.}$ limiting. The characteristics of the condition are $\overrightarrow{\vec{\omega}}$ (i) a sudden explosive illness in the midst of $\mathscr{D}$ apparent health and without previous warning;응 (ii) rapid evolution of necrosis and sloughing of 3 . the tissues; (iii) apparent absence of the usual causes of gangrene; (iv) termination by complete cure; (v) mixed bacteriological picture. According to Mair (1945) the features are pain, prostra- if tion, pallor and pyrexia, the scrotal discharge having a particularly fœtid odour, as in the $\frac{\text { ? }}{5}$ present case.

Gibson (1930) analysed 206 cases from the $\mathscr{\Phi}$ literature and found a mortality rate of $27 \%$, but $\frac{\bar{D}}{\mathbb{D}}$ with modern antibiotics death would appear to be $\frac{D}{3}$ rare. In 1920 Randall was quoting a $32 \%$ mor 음 tality. Gibson regarded the condition as a gos gangrene with secondary streptococcal infection as gas is occasionally present in the tissues, bri as a general rule clostridia are not found in cuF tures of the pus. Carver (I939) obtained a pure growth of streptococci, but a single growth has not been obtained by other investigators and, as

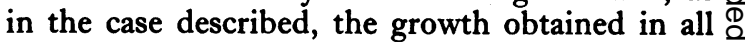
other cases was mixed, at least three organisms $\overrightarrow{\vec{B}}$ being present. It is therefore impossible to decide which is the instigator.

The ætiology is also in doubt. It is not a gas ? gangrene as clostridia are not always present, and the condition does not really resemble an ery- 3 sipelas. Mansfield (I946) postulated an infective thrombosis of the septal vessels, but it is more likely that the latter is a secondary effect due to $\delta$ the violent inflammation of the tissues. There is some similarity to Meleney's (1924) ulcer of the 윽 abdominal wall, which he describes as a post- $D$ operative progressive synergistic bacterial gan- 을. grene'. The latter is caused by the Staphylococcus $\bar{N}$ aureus and a micro-aerophilic non-hæmolytic streptococcus acting in symbiosis, the staphylo- $N$ coccus being derived from the air and the strepto- $N$ coccus from the alimentary tract. Campbell (r922) thought that the streptococcus in one or other 0 form is responsible, and the same view was held $\overparen{\complement}$ by Fournier's pupils early in the century. In $\stackrel{\mathcal{+}}{+}$ many cases there is a history of a neighbouring ${ }^{\top}$ lesion or operation, and in an analysis of 240 cases 
Mair (1945) found a clear history of antecedent trauma or septic foci. Fournier's gangrene has been described as occurring after urethroscopy, injection treatment for fissure-in-ano, radical cure of hydrocele, and in Randall's (1920) case there was a chancroid lesion on the penis.

Aird (1949) states that Fournier's gangrene follows extravasation of urine and Campbell (1922) postulated the same cause, but this is certainly not always the case. The latter author remarked that the condition is not always 'idiopathic' or 'spontaneous'. He classified the causes of gangrene of the scrotum as follows:

(I) Due to systemic diseases such as measles or smallpox, or metabolic diseases such as diabetes.

(2) Due to urinary extravasation.

(3) Due to trauma.

(4) Due to a local inflammatory process, such as venereal or pyogenic inflammation of the genitalia, or associated with a process not located in the genitalia, such as umbilical sepsis in infants.

(5) Spontaneous gangrene with no demonstrable portal of entry.

Group (5), according to Campbell, seems to be the only category into which to place Fournier's gangrene. The remainder would appear to be a form of phagædena.

Thomas (1956) analysed eight cases of Fournier's gangrene and found that the preceding malaise varied from 5 to 15 days. The maximum temperature was $105^{\circ}$ and the mode of onset was a painful swelling of the scrotum with much cdema. In one case the under surface of the penis was also involved. The bacteriology in every case was mixed, and Thomas also noted the mildness of the toxæmia in West Africans, which he thought was due to their natural resistance.

It is suggested that treatment of Fournier's gangrene should be on general lines, with excision of sloughs at the appropriate time and treatment with antibiotics. Campbell (1922) suggests irrigation with hydrogen peroxide and zinc peroxide dressings, and recommends that after the sloughs have separated the healthy edges of the scrotum should be sutured together to assist healing. Linder and Levitas (1932) comment adversely on the scarring and immobility of the testicles after spontaneous epithelialization, and recommend skin grafting. When there has been much destruction of tissues Wetherall (1945) describes a technique for stretching the neighbouring skin, but if a shortened convalescence is desired a less complicated procedure in the form of Thiersch grafting would appear to be satisfactory. No such procedure was necessary in the case described, but unfortunately a late follow-up has not been possible to examine the state of the scrotum and testes, and to note whether any improvement in the treatment given might have been advantageous.

\section{Summary}

A case of Fournier's gangrene of the scrotum is described and the literature is reviewed. The relative rarity of the condition is noted, and the xtiological factors are discussed. It is noted that the use of antibiotics has made a considerable difference in the treatment, and results in a much quicker resolution of the condition.

I am indebted to Mr. D. H. C. Harland for permission to publish this case, and for much helpful advice and criticism; and to Mr. G. B. Farlam for assistance with translation from the French of $M$. Fournier's original article.

\section{REFERENCES}

AIrd, I. (1949): Companion in Surgical Studies, p. 981.

Campbell, M. F. (1922): Fournier's Gangrene, Surg. Gynec. Obstet., 34, 780

Carver, J. (1939): Idiopathic Gangrene of the Scrotum, Brit. F. Urol., Ix, 68.

Fournier, J. A. (1883): Med. Pract., 4, 589. (1883): Sem. Méd. (Paris), 3, 345.

(1884): Ibid., 4,69 .

(1885): Your. Méd. Chir. Prat., 56, 158.

Gibson, T. E. (1930): Gangrene of the Scrotum, F. Urol. (Baltimore), $23,125$.

Linder, W., and Levitas, M. S. (1932): Fournier's Gangrene, Amer. Y. Surg., i6, 526.

MaIR, G. B. (1945): Idiopathic Gangrene of the Scrotum, Lancet, i, 464.

Mansfield, O. T. (1946): Spontaneous Gangrene of the Scrotum, Brit. $f$. Surg., 33, 275.

Meleney, F. L. (1924): Gangrene of the Skin, Arch. Surg. (Chicago), r31, 129. (1931): Gangrene of the Skin, Ann. Surg., 94, 961.

(1933): Gangrene of the Skin, Surg. Gynec. Obstet., 56, 847.

Randall, A. J. (1920): Fournier's Gangrene: Report of a Case, $\mathcal{F}$. Urol. (Baltimore), $4,289$.

Thomas, J. F. (1956): Fournier's Gangrene of Penis and Scrotum, Amer. F. Urol., 475.

Wetrerel, F. S. (1945): Management of Gangrene of the Scrotum, and Report of Cases, Surgery, I8, 525. 